\title{
Confronting the biodiversity crisis
}

\author{
In 2002, the world's governments agreed to significantly slow the rate of biodiversity loss by 2010. \\ Time is almost up, and by most accounts they've failed. Now that climate change is emerging \\ as one of biodiversity's greatest threats, scientists are proposing new ways to tackle the crisis.
} Hannah Hoag reports.

\section{BARCODING LIFE}

In July 2009, for the fourth year in a row, a swarm of biologists fanned out across the tundra near Churchill, Manitoba, in northern Canada. They plucked fragments of plants and animals - feathers and fur, mayflies and moths - from land, lakes, rivers and ocean. At the lab, the specimens were ground up and identified using short stretches of DNA - a unique barcode for every species. So far, the team - led by Paul Hebert, an evolutionary biologist at the University of Guelph in Canada, who invented DNA barcoding (Proc. $R$. Soc. B 270, 313-321; 2003) to speed up the process of taxonomy - has identified more than 4,000 species from its northern expeditions, including parasitic wasps that have been observed across North America but were previously overlooked in the Canadian Arctic.

"The first business of conservation is telling species apart," says Hebert. Before barcoding, biological specimens were identified on the basis of morphology, behaviour and genetics. The technique will offer a "quantum jump" in the rate that species are registered, says Hebert. What once took months can now take a few hours. It also gives biodiversity a boost: barcoding has repeatedly shown that one species is, in fact, three, or ten (Evol. Biol. 7, 121; 2007).

Dan Janzen, a tropical ecologist and conservation biologist who splits his time between the University of Pennsylvania in Philadephia and the Area de Conservación Guanacaste (ACG) in Costa Rica, sees the value in DNA barcoding. He is charged with identifying the estimated 12,500 species of caterpillar in the ACG - an area the size of New York City and its suburbs. In his years of studying this conservation area, he has witnessed changes in biodiversity. For one, the species he studies are moving up the mountains.

In the 1990s and earlier, the common caterpillar Copaxa rufinans could be found at elevations between 400 and 1,200 metres in the rainforests of ACG. Its more localized relative, Copaxa curvilinea, lived at lower elevations - between 100 and 500 metres in ACG. In the past decade, caterpillars

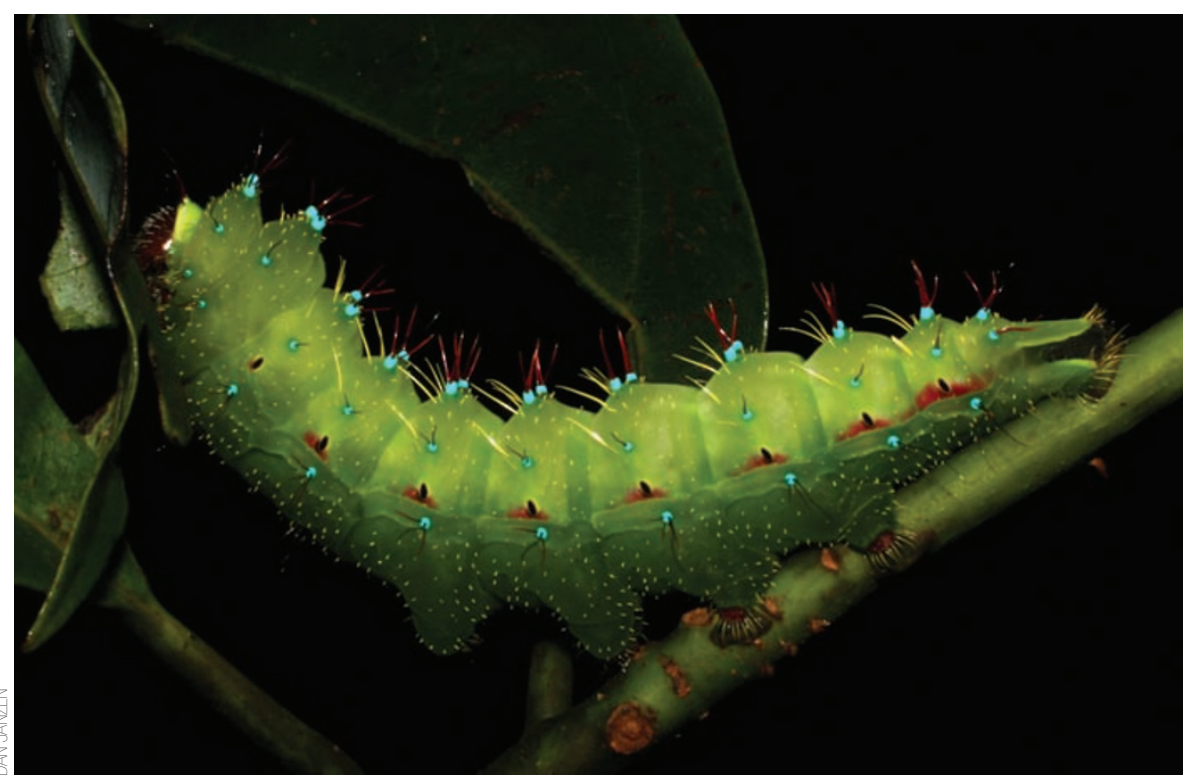




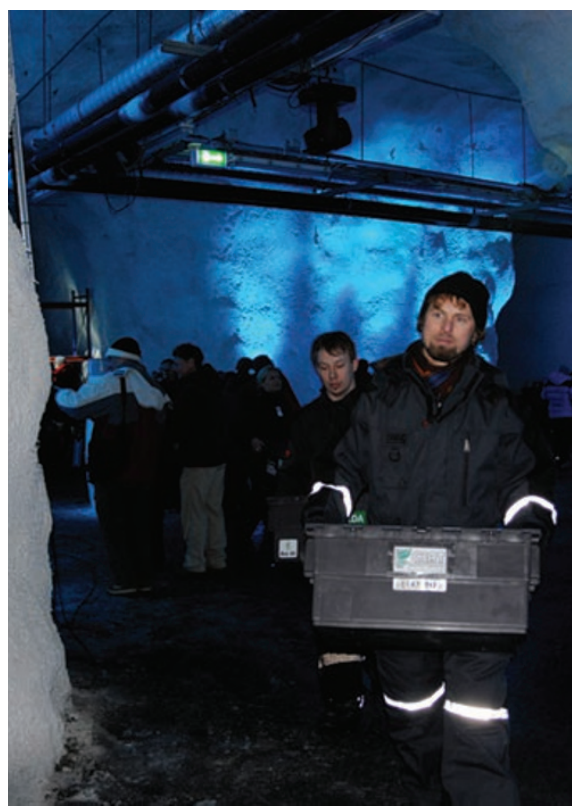

Boxes of seeds arrive from around the world to the Svalbard vault.

predicted to fall by as much as 30 per cent if temperatures rise $1{ }^{\circ} \mathrm{C}$ (Science

$319,607-610 ; 2008)$. And with a $2{ }^{\circ} \mathrm{C}$ temperature rise, more than 80 per cent of the land area over most African nations would be climatically unsuitable for the crops now growing there (Glob. Environ. Change 19, 317-325; 2009). "That would be a food crisis," says Cary Fowler, executive director of the Global Crop Diversity Trust. Fowler says it's likely that farmers will have to adapt their agricultural practices by using analogous crops from other locations in the future. But if today's varieties do not adapt to tomorrow's climates, new varieties containing traits for drought tolerance or pest resistance, for example, could be bred using seeds from global seed banks, or from the Svalbard vault, as a last resort.

Domesticated crops aren't the only ones at risk: as many as 16 to 22 per cent of the wild relatives of cowpea, peanut and potato could go extinct by 2055, according to one study (Agric. Ecosys. Environ.

126, 13-23; 2008). Experts such as

Kenneth Street, a genetic resource scientist at the International Center for Agricultural Research in the Dry Areas, in Aleppo, Syria, are tracking down these wild relatives, which could be used to boost a crop's genetic diversity and resilience to climate change. Using electronic maps that show soil type and climate, these modern-day seed hunters identify environments with conditions that favour genetic diversity. "Usually, we travel to high lands or marginal lands where modern varieties couldn't grow, where farmers are eking out an existence with marginal crops or still using traditional varieties," says
Street. "We concentrate on areas that are likely to have drier, or hotter, or more salty conditions." A recent expedition to Tajikistan led Street to a remote village where farmers handed him a collection of wheat seeds, one of which offered resistance to Sunn pest, an insect that favours warmth and destroys cereal crops in warm dry areas. "We are continually on the hunt for novel sources of resistance," he says.

"To some, agriculture is the enemy in the climate change debate - it is the source of a lot of greenhouse gases," says Fowler. "But we have to make sure that agriculture adapts. If it doesn't, all our other efforts on climate change are down the drain."

\section{PUTTINGA PRICE ON NATURE}

Nine watersheds tumble into Cauca Valley, a region in the southwest of Colombia sandwiched between two Colombian Andean mountain chains. For centuries, its richness has attracted humans, who exploited the valley's resources first for agriculture and stockbreeding, and later for hydroelectric power generation. Today, sugar cane production dominates the valley's industry.

"There are many stresses from water use. The sugar cane sector is thirsty, but the people who live there also need it for daily activities and for drinking water," says Alejandro Calvache, a water fund specialist at The Nature Conservancy (TNC) based in
Cartagena, Colombia. TNC, in collaboration with the sugar cane growers' association, the regional environmental authority and several grassroots organizations, is building a water fund that will oversee a massive program of reforestation, water protection, soil improvements, education and training. By investing in the region's ecosystem services, the project, which is called 'Agua Por La Vida y la Sostenibilidad' - meaning 'Water for Life and Sustainability' - aims to lessen climate change impacts and threats to biodiversity.

Water funds exist globally to conserve watersheds, but this is one of the first to include climate change modelling to help direct investments. The International Center for Tropical Agriculture, a research institute in Colombia, is modelling scenarios to determine the effects of climate change on local water resources. These scenarios are then fed into a computer-based decisionmaking tool called InVEST, which has been developed by the Natural Capital Project, a partnership between TNC, Stanford University and the World Wildlife Fund. InVEST identifies the areas where climate change is unlikely to threaten activities the water fund has been invested in - such as promoting the reforestation of a hillside or teaching eco-friendly cattle-ranching practices - and their returns. "Traditionally, conservation has pulled on people's heartstrings," says Heather Tallis, lead scientist at Natural Capital. "We try to appeal to people's lifeblood, like drinking water."

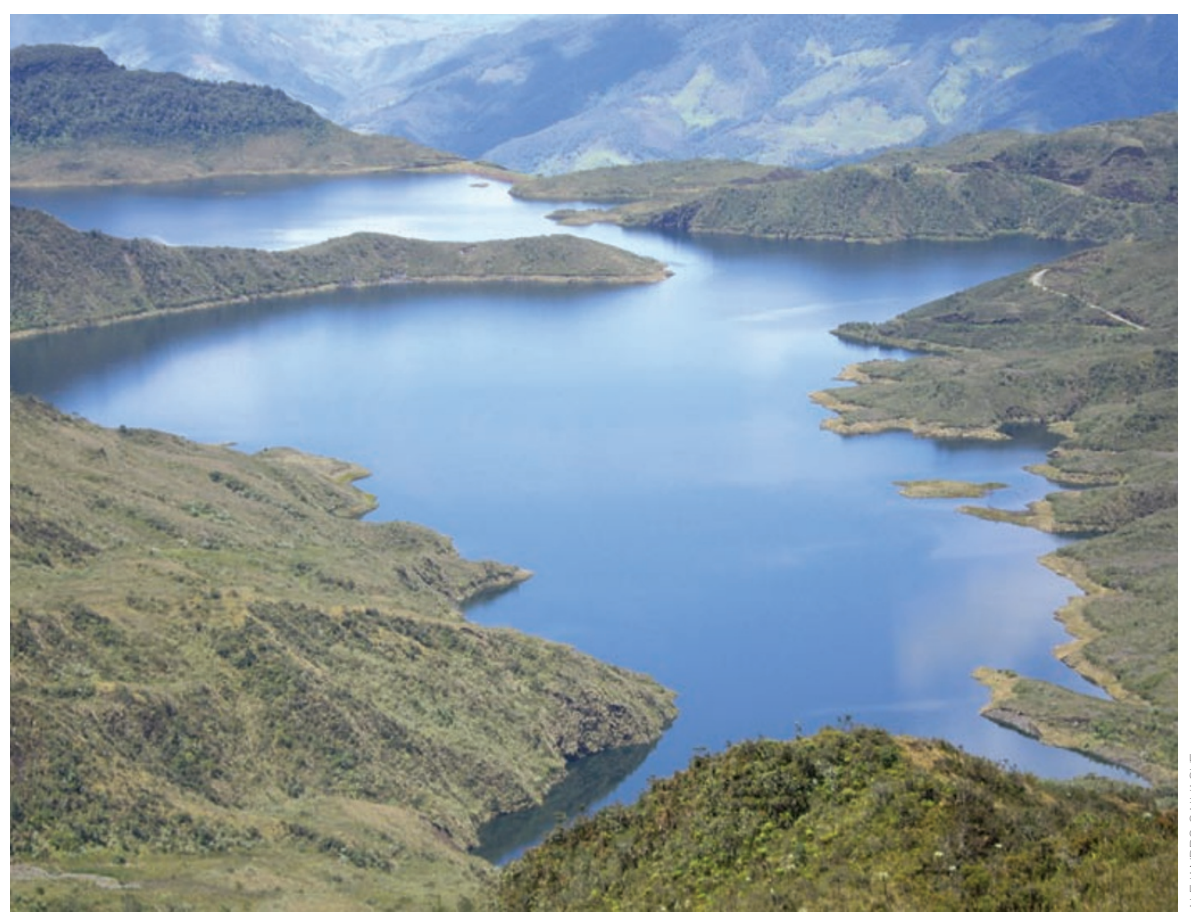

The Nature Conservancy has made conservation investments in Colombian watersheds, including Chingaza National Park, which provides water to Bogotá. 
Some researchers caution, however, that accurate regional climate change forecasts are still fraught with uncertainty (Nature 463, 284-287; 2010), so care is warranted in relying on them to direct investment decisions. But Calvache says one of the strengths of the climateinfluenced approach is its flexibility. "You can invest money, see what happens and see if those were the best returns in terms of conservation goals," he says. "There are many uncertainties in climate change ... being flexible is extremely important."

\section{SHIFTING SPECIES}

In the 1970s, the purple finch was a frequent visitor to American bird feeders. The reddishcoloured bird would breed in Canada in the summer, and winter in the central and southern United States. Forty years later, its flight patterns have changed. As temperatures have increased, its southern migrations have shortened by about 700 kilometres.

Some species have shifted their ranges in response to climate change, but not all will be able to keep pace. That realization radicalized Camille Parmesan, an integrative biologist at the University of Texas at Austin. She figured out that some threatened species could be rescued by deliberately removing them from dead-end locations and relocating them to more appropriate climes, an intervention dubbed 'assisted migration', 'assisted colonization' or 'managed relocation' (Science 321, 345-346; 2008).

There have been few incidences of assisted relocation thus far, and Parmesan hasn't had a hand in any of them. But that may soon change. Parmesan is suggesting the US Fish and Wildlife Service use managed relocation to save the Laguna mountain skipper, a small, black-and-white endangered butterfly found on only two or three mountaintops in southern California. "There are mountains nearby, further north, some of which have higher elevations and have the host plants. It could easily be moved without a lot of consequences," says Parmesan.

But others aren't convinced of the merits of assisted migration. "It's ecological gambling," says Anthony Ricciardi, an invasive-species biologist at McGill University in Montreal. "We do not have a sufficient understanding of the impact to engage safely in assisted colonization on a frequent basis." The risks aren't empty. Whether the species in question is an American pica or a torreya pine, its intentional introduction could transfer disease into new host species, or it could become invasive and wipe out the destination's native fauna

"You might have really good intentions, but in many cases it will come with a large risk," says Jessica Hellmann, a conservation

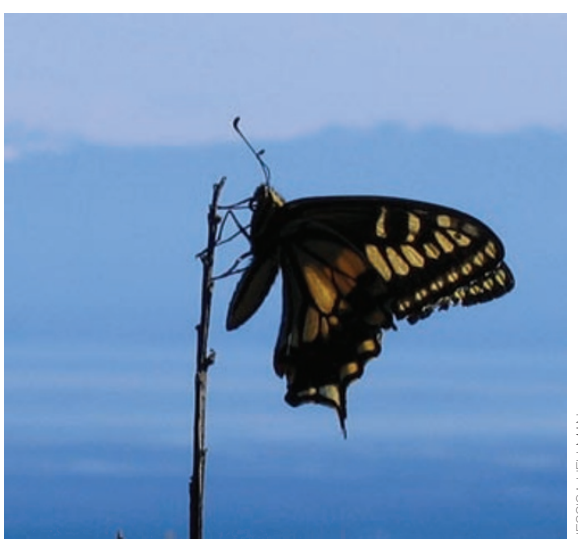

The swallowtail butterfly, one candidate species for assisted relocation.

biologist at the University of Notre Dame in Indiana who recently proposed a decisionmaking framework for 'managed relocation' that can help characterize uncertainty and establish priorities (Proc. Natl Acad. Sci. USA 106, 9721-9724; 2009). Ricciardi points out that unless you address the root causes of climate change, assisted migration "will temporarily save a species at best, until you have to move it again". Still, says Parmesan, "This tiny amount of warming is already causing conservation problems. You've got to be willing to do something that's a little more risky. There is no no-risk option."

\section{A MOVEABLE PARK}

Over the year, the endangered loggerhead turtle meanders through the ocean, foraging on jellyfish and crustaceans along sea surface temperature fronts. The position and intensity of these thermal gradients, which are set up by ocean circulation, are expected to shift with climate change, altering the turtles' preferred locations. But where and when they'll move is uncertain. The loggerhead's dynamic range means that stationary marine protected areas may not adequately protect the turtle. But a mobile protective area that moves in space and time, following sea surface temperature fronts, just might do the job (Conserv. Biol. 24, 70-77; 2010).

Traditional conservation approaches assumed species ranges would always stay in the same place: if you protected the geographic region, the species within it would be protected forever. But species don't stay put when temperatures move outside their comfort range. This realization has changed the way people think about conservation strategies, says Lee Hannah, a senior scientist in climate change biology at Conservation International's Center for Applied Biodiversity Science in Santa Barbara, California.

Most fishing vessels are equipped with global positioning systems, which make moving, irregular take and no-take zones possible. "It's a high-tech concept whose time has come," says Hannah. "If you could set that up then you don't have to have a perfect crystal ball. Your protection evolves as it needs to."

The concept could be applied more broadly to other marine species, such as sharks or whales, and to land-based

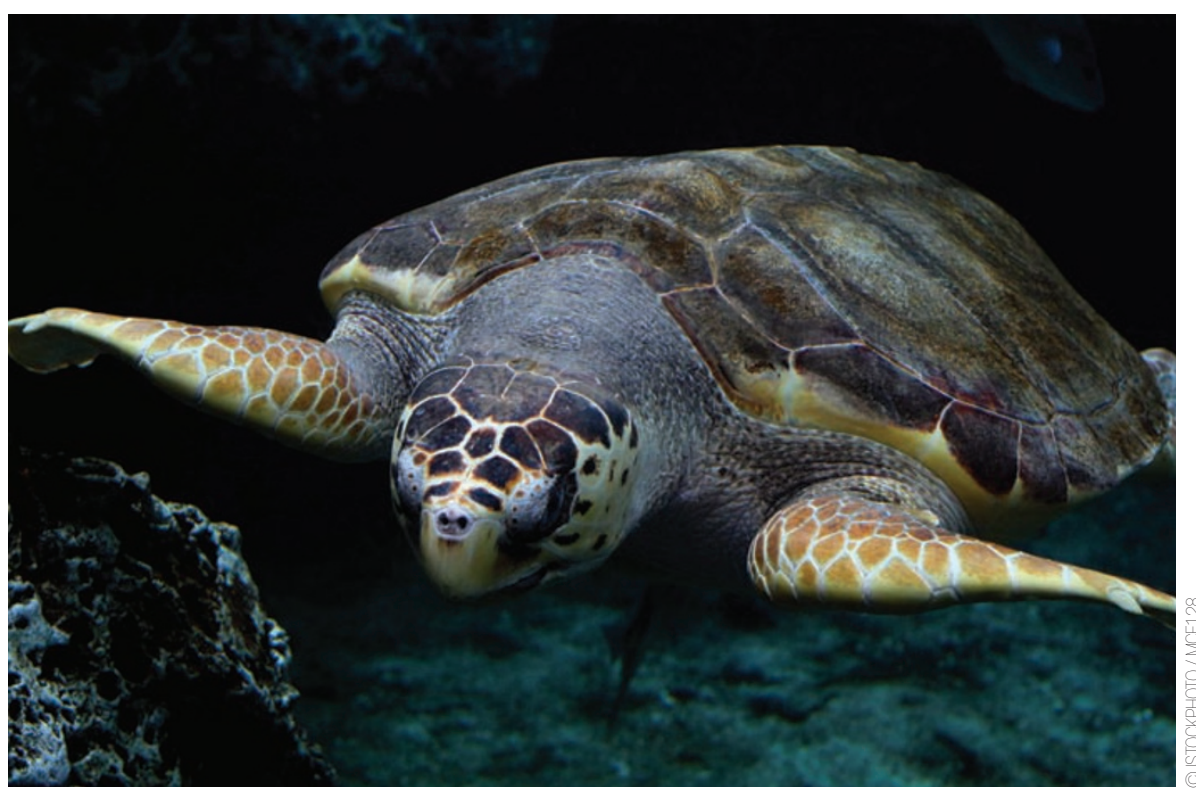

Loggerhead turtles could benefit from flexible conservation areas that move with shifting ocean temperature gradients. 
animals. A whole population of animals threatened by climate change could be tagged with microscopic trackers and followed through space and time, allowing the protected space to be modified as the animals move seasonally to feed and breed.

\section{AN IPCC FOR BIODIVERSITY}

Come June, biologists and policymakers will gather in South Korea to discuss the future of a proposed scientific panel to monitor biodiversity and offer advice on its protection. Although the idea for the panel, which would compare in scope and size with the Intergovernmental Panel on Climate Change (IPCC), was first discussed publicly at a 2005 international conference on biodiversity in Paris (Nature 442, 245-246; 2006), it has recently gained momentum. At the launch of the International Year of Biodiversity in Berlin in January, German Premier Angela Merkel championed its creation.

Says Neville Ash, the head of ecosystem management at the International Union for the Conservation of Nature, in Geneva, "When you think about climate change, the IPCC is the standard authoritative reference on the state of the science. That is entirely missing on the state of biodiversity and ecosystem services. If you're a policymaker at the international level, there isn't a single consolidated and robust source of science on biodiversity and ecosystem services to turn to."

Like the IPCC, the Intergovernmental Platform on Biodiversity and Ecosystem Services (IPBES) would improve the links between science and policy, and ensure decisions are based on the best

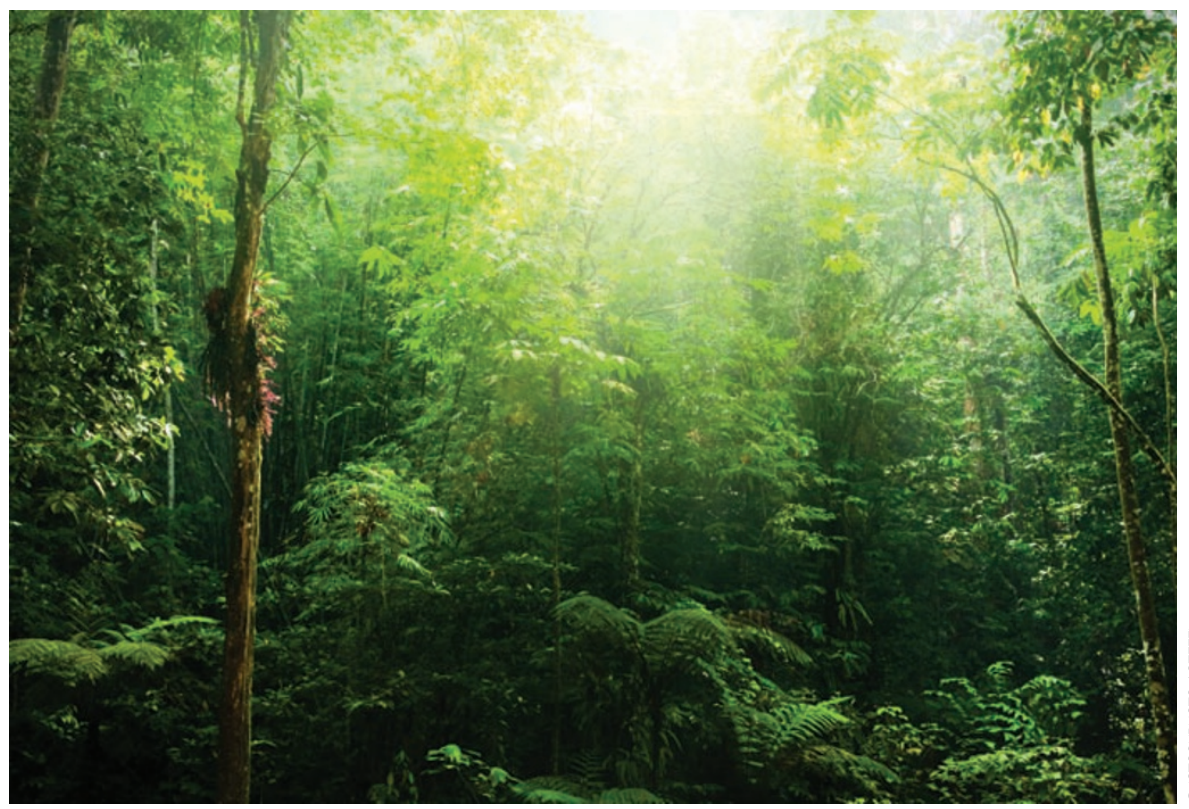

The IPBES would offer scientific advice to governments on the societal services provided by ecosystems such as rainforests.

available science (Curr. Opin. Environ. Sustain. doi:10.1016/j.cosust.2010.02.006; in the press). It would oversee global and regional biodiversity assessments, identify and analyse trends, and explore future changes. It would also invest in training. "Scientific capacity around the globe is not equal," says Harold Mooney, an environmental biologist at Stanford University and the chair of Diversitas, an international programme of biodiversity science. "Capacity building is one of the pillars of the programme."

Though scientists are generally supportive of the idea, some are concerned that the IPBES will consume the lion's share of their research time and that its impact is unsure. "Basic research on climate systems gets shunted aside in order to get the 'products' out that have been promised to policymakers in each IPCC report," says Parmesan. "What has to be considered is whether the trade-off [of] good policies gained by such an assessment would be worth the good science lost."

Published online: 5 May 2010

doi:10.1038/climate.2010.38

Hannah Hoag is a freelance writer based in Montreal. 